\title{
NITROGÊNIO NA ADUBAÇÃO QUIMICA DO CAFEEIRO: DOSES E PARCELAMENTOS DO NITROCÁLCIO (1)
}

\author{
GENÉSIO DA SILVA CERVELLINI $(2,5)$, SÉRGIO VASCO DE TOLEDO $\left({ }^{2}\right)$, \\ ANTONIO JUNQUEIRA REIS $\left({ }^{3}\right)$ e TÚLIO RIBEIRO ROCHA $\left({ }^{4}\right)$
}

\begin{abstract}
RESUMO
Nitrocálcio nas quantidades de $60,120,180$ e 240 gramas de $N$ por cafeeiro e por ano foi aplicado em parcelamentos diferentes, de acordo com os tratamentos e em três locais com início em 1973/74: Centro Experimental de Campinas, Estação Experimental de Mococa e Estação Experimental de Ribeirão Preto. Foram estudados os efeitos das quantidades crescentes e avaliadas as conveniências do parcelamento das doses de $\mathrm{N}$ aplicadas. Os acréscimos de produção com a elevação dessas doses foram bastante grandes até $120 \mathrm{~g}$, passando, a partir dessa quantidade, a aumentos menores. Os efeitos residuais do sulfato de amônio, Nitrocálco, uréia e salitre-do-chile aplicados quatro anos antes do início do experimento ainda afetaram as produçōes, passados dez anos das áltimas aplicaçōes, reduzindo-as mais para as correspondentes ao salitre-do-chile e uréia. Os parcelamentos utilizados não favoreceram dados consistentes para conclusōes, devendo seu estudo ter continuidade em novas séries de ensaios.
\end{abstract}

Termos de indexação: cafeeiro; adubaçāo; nitrogênio; doses; parcelamentos; efeitos residuais.

\footnotetext{
(1) Recebido para publicaçăo em 19 de setembro de 1984.

(2) Seção de Café, Instituto Agronómico (IAC), Caixa Postal 28, 13001 Campinas (SP).

( $\left.{ }^{3}\right)$ Estação Experimental de Ribeirāo Preto, IAC.

(4) Estação Experimental de Mococa, IAC.

(5) Com bolsa de suplementação do CNPq.
} 


\section{INTRODUÇÃO}

O parcelamento das aplicações de fertilizantes químicos lixiviáveis, especialmente os nitrogenados, é largamente recomendado para diversas culturas, como recurso para reduzir as perdas dos nutrientes, assegurando maior disponibilidade às plantas durante o ciclo de desenvolvimento, quando estas atingem estádios máximos de absorção e transformação metabólica.

Trabalhos anteriores sobre a adubação nitrogenada do cafeeiro, conduzidos no Centro Experimental de Campinas (MORAES et alii, 1976) e Estações Experimentais de Mococa e Ribeirāo Preto (MORAES et alii, 1985), comparando os fertilizantes sulfato de amônio, Nitrocálcio, uréia e salitre-do-chile, aplicados em doses crescentes e em diferentes parcelamentos, não apresentaram resultados consistentes e conclusivos para uma definição de procedimento ideal na aplicação dos fertilizantes nitrogenados, especialmente quanto ao número e épocas mais indicados. Procurando melhores indicações e tomando esse objetivo como o principal, iniciou-se nova fase de estudo nos três locais referidos, utilizando-se apenas o Nitrocálcio como fonte de nitrogênio e elevando-se as doses anuais de 60 até $240 \mathrm{~g}$ de nitrogênio por cova.

Considerando o efeito residual de cada fonte utilizada, MORAES et alii (1976) verificaram, através de análises do solo, que houve acidificação como resultado das aplicações dos fertilizantes nitrogenados, tendo o salitre-do-chile provocado ligeiro decréscimo do $\mathrm{pH}$ e reduzido os teores de cálcio e magnésio do solo. O Nitrocálcio proporcionou maior abaixamento do $\mathrm{pH}$, reduzindo também os teores de cálcio e de maganésio do solo. A uréia e o sulfato de amônio abaixaram $\mathrm{opH}$ acentuadamente, ocorrendo o mesmo com os teores de cálcio e de magnésio, de tal modo que houve aparecimento de alumínio livre no solo. As análises das folhas confirmaram este efeito de acidificação, demonstrando ter havido liberação de manganês e alumínio na solução de solo, especialmente quando a fonte utilizada fora o sulfato de amônio.

MORAES et alii (1979) encontraram uma diminuição dos teores de manganês nas folhas quando utilizaram o salitre-do-chile, e aumentos consideráveis daqueles teores quando utilizaram uréia, sulfato ou nitrato de amônio. Os teores de alumínio foram ligeiramente aumentados com o emprego de uréia e sulfato de amônio. Nesse mesmo trabalho, verificaram que o salitre-do-chile provocou a elevação do $\mathrm{pH}$ dos solos, enquanto a uréia e o sulfato de amônio causaram seu abaixamento e concomitante elevação dos níveis de alumínio e manganês livres.

O presente experimento teve como objetivo estudar o efeito de doses crescentes de nitrogênio, maiores que as estudadas no anterior, cuja dose máxima foi $180 \mathrm{~g}$ de $\mathrm{N}$ por planta, e observar os efeitos do seu fracionamento, considerando que os resultados anteriores não haviam sido consistentes. 


\section{MATERIAL E MÉTODOS}

Foi aplicado o Nitrocálcio contendo $27 \%$ de N, para fornecimento de 60 , 120,180 e 240 gramas de $N$ por ano e por cova. As parcelas experimentais eram as mesmas dos experimentos anteriores (MORAES et alii, 1976, 1985), constituidas por 16 covas dispostas em quatro linhas de quatro covas. cada uma, segundo o espaçamento de $3 \times 2 \mathrm{~m}$, com duas plantas por cova. Os tratamentos foram distribuídos de modo que se separassem os efeitos residuais das fontes anteriomente utilizadas: sulfato de amônio, Nitrocálcio, uréia e salitre-do-chile. Os experimentos anteriores envolviam quatro doses de quatro fontes de $\mathrm{N}$ aplicadas seguindo quatro fracionamentos diferentes, sem repetições. Os tratamentos utilizados estão no mesmo campo experimental, com quatro repetições, uma para cada fonte anterior, mantendo-se as proporções para as doses, isto é: onde anteriomente havia sido aplicada urna dose menor, empregou-se a menor, ocorrendo o mesmo para as outras três doses.

O tratamento em que a quantidade de $240 \mathrm{~g}$ de $\mathrm{N}$ seria aplicada em uma só vez, em outubro, foi transformado em testemunha, sem aplicação de $\mathrm{N}$.

As plantas com aproximadamente dez anos de campo foram recepadas em 1972, recebendo apenas $60 \mathrm{~g}$ de $\mathrm{N}$ em 1973; 60 e $120 \mathrm{~g}$ de $\mathrm{N}$ em 1974. A partir de 1975, passaram a receber as quantidades de acordo com os tratamentos.

Em Mococa, as plantas foram decotadas em 1971 e, a partir de 1974, receberam as doses de $\mathrm{N}$ de acordo com os tratamentos. Em outubro de 1974, todas as parcelas dos três locais foram amostradas, retirando-se o solo até $20 \mathrm{~cm}$ de profundidade de área sob os ramos do cafeeiro. As amostras foram analisadas no laboratório da Seção de Fertilidade do Solo e Nutrição de Plantas, encontrando-se suas médias no quadro 1.

Em novembro de 1974, foi aplicado $1 \mathrm{~kg}$ de calcário dolomítico por cova e, a partir de 1975, $40 \mathrm{~g}$ de superfosfato simples, $30 \mathrm{~g}$ de cloreto de potássio e $10 \mathrm{~g}$ de bórax, uma só vez por ano.

Foram colhidas amostras de folhas de todas as parcelas, nos três locais, de 1976 até 1977. Do material ànalisado na Seção de Fertilidade do Solo e Nutriçăo de Plantas, aproveitaram-se apenas os dados de $\mathrm{N}$ apresentados nos quadros 2,4 e 6.

Os parcelamentos estudados foram os seguintes:

1. Quantidade de N aplicada totalmente em outubro;

2. Idem em dezembro;

3. 2/3 da quantidade de $\mathrm{N}$ aplicada em janeiro e 1/3 em outubro;

4. $1 / 6$ da quantidade de $N$ aplicada em outubro; $1 / 3$ em dezembro; $1 / 3$ em janeiro e $1 / 6$ em fevereiro.

Foram colhidos os dados de produção das quatro covas centrais de cada canteiro e o rendimento baseado nas amostras retiradas do café de colheita, as quais foram secas e processadas separadamente. 
Os dados climáticos foram gentilmente cedidos pela Seção de Climatologia Agrícola do Instituto Agronômico.

QUADRO 1. Análise de solo, média dos dados obtidos em dezesseis canteiros com doses e parcelamentos diferentes

\begin{tabular}{lllll}
\hline Fontes (1) & $\mathrm{pH}$ & $\mathrm{K}$ & $\mathrm{Ca}+\mathrm{Mg}$ & $\mathrm{Al}$
\end{tabular}

\begin{tabular}{lllll}
\hline \multicolumn{4}{c}{ Campinas } \\
N & 5,98 & 0,64 & 3,93 & 0,14 \\
SA & 5,20 & 0,50 & 2,06 & 0,55 \\
U & 5,80 & 0,72 & 3,21 & 0,19 \\
SC & 5,97 & 0,76 & 3,06 & 0,09 \\
SN (2) & 6,01 & 0,88 & 3,20 & 0,06 \\
\hline
\end{tabular}

Mococa

\begin{tabular}{lllll} 
N & 5,20 & 0,54 & 2,09 & 0,28 \\
SA & 4,51 & 0,34 & 0,94 & 1,15 \\
U & 4,91 & 0,45 & 1,42 & 0,50 \\
SC & 5,77 & 0,75 & 2,66 & 0,05 \\
SN & 5,45 & 0,56 & 2,30 & 0,13 \\
\hline
\end{tabular}

Ribeirão Preto

\begin{tabular}{lllll} 
N & 4,74 & 0,30 & 2,60 & 0,34 \\
SA & 4,22 & 0,25 & 1,14 & 1,04 \\
U & 4,48 & 0,31 & 1,68 & 0,69 \\
SC & 5,01 & 0,52 & 2,68 & 0,22 \\
SN & 5,13 & 0,41 & 0,41 & 0,16 \\
\hline
\end{tabular}

(1) As fontes indicadas foram aquelas utilizadas no ensaio anterior: N: Nitrocálcio; SA: sulfato de amônia; U: uréia e SC: salitre-do-chile. (2) SN: sem nitrogênio.

\section{RESULTADOS E DISCUSSÃO}

Para avaliação dos efeitos das aplicaçōes de nitrogênio são apresentadas nos quadros 2, 4 e 6 as produções médias das quatro repetições e quatro parcelamentos com os correspondentes teores de $\mathrm{N}$, e nos quadros 3,5 e 7, os 
dados de precipitações pluviais e deficiências hídricas acumuladas por mês, para os anos agrícolas referentes às colheitas de café realizadas durante o periodo do experimento.

As produções anuais são apresentadas unicamente para melhor avaliação dos efeitos climáticos, uma vez que, pela própria natureza do cafeeiro, existe uma oscilação característica de produção bianual. Para avaliação dos efeitos de tratamento, são examinadas apenas as médias de produções obtidas durante quatro anos consecutivos, reduzindo-se assim os efeitos da oscilação da produção.

As precipitações pluviais, além de outros efeitos, influenciam na absorção do nitrogênio, por oferecer condiçōes de lixiviação, diminuindo o nitrogênio disponivel e proporcionando melhores condições de desenvolvimento dos ramos que produzirão a florada no ano seguinte, considerando que os primórdios das flores se formam juntamente com os ramos.

A deficiência hídrica, ocorrida mais comumente nos meses de inverno, provoca uma reduçāo no metabolismo da planta e na absorção por fluxo de massa, forma como é absonida a maior parte do nitrogênio.

\subsection{Experimento do Centro Experimental de Campinas}

Conforme os resultados obtidos no Centro Experimental de Campinas Quadro 2 - a elevação de produção obtida com $120 \mathrm{~g}$ de $\mathrm{N}$ foi da mesma ordem de grandeza daquelas obtidas com 180 ou $240 \mathrm{~g}$, e superiores às conseguidas com $60 \mathrm{~g}$ de $\mathrm{N}$ a $1 \%$ de probabilidade. As doses de 180 e $240 \mathrm{~g}$ de $\mathrm{N}$ por planta proporcionaram apenas 4 e $15 \%$ a mais que a de $120 \mathrm{~g}$.

Os dados do quadriênio, obtidos das parcelas com várias épocas de aplicação do $\mathrm{N}$, não mostraram diferenças significativas a $5 \%$ de probabilidade. Novos estudos do parcelamento estão sendo iniciados.

O efeito das fontes anteriormente utilizadas, até $1 \%$ de probabilidade, foi de maior produção para as parcelas que recebiam sulfato de amônio ou Nitrocálcio, não havendo diferenças entre elas. As produções das parcelas que recebiam uréia ou salitre-do-chile também não se diferenciaram entre si.

As produções anuais mostraram ter havido o ciclo bianual, não havendo, no periodo, grande excesso ou escassez de chuvas - Quadro 3 - não se determinando periodos com grandes deficiências hídricas capazes de influenciar significativamente as produções dos cafeeiros.

\subsection{Experimento da Estação Experimental de Mococa}

Os dados da Estação Experimental de Mococa - Quadro 4 - mostram também que a elevação de produção obtida com $120 \mathrm{~g}$ de $\mathrm{N}$ por planta foi maior 
que com $60 \mathrm{~g}$,e que as elevações de produções obtidas com 180 e $240 \mathrm{~g}$ de $\mathrm{N}$ por planta não foram muito maiores que com $120 \mathrm{~g}$. Esses resultados, a $1 \%$ de probabilidade, mostram que a produção obtida com $120 \mathrm{~g}$ de $\mathrm{N}$ é $46 \%$ maior que com $60 \mathrm{~g}$, e as produções obtidas com 180 e $240 \mathrm{~g}$ de $\mathrm{N}$ são $4 \%$ e $16 \%$ maiores que com 120g.

QUADRO 2. Produção de café beneficiado e teor de $\mathrm{N}$ na folha (verão) obtidos no Centro Experimental de Campinas

\begin{tabular}{|c|c|c|c|c|c|c|c|c|}
\hline \multirow{2}{*}{$\frac{N \text { aplicado }}{\text { (g/cova) }}$} & \multicolumn{2}{|c|}{$1976 / 77$} & \multicolumn{2}{|c|}{$1977 / 78$} & \multicolumn{2}{|c|}{$1978 / 79$} & \multirow{2}{*}{ 1979/80 } & \multirow{2}{*}{$\begin{array}{l}1976 / 80 \\
\mathrm{~kg} / \mathrm{ha}\end{array}$} \\
\hline & $\% \mathbf{N}$ & $\mathrm{kg} / \mathrm{ha}$ & $\% \mathrm{~N}$ & $\mathrm{~kg} / \mathrm{ha}$ & $\% \mathrm{~N}$ & $\mathrm{~kg} / \mathrm{ha}$ & & \\
\hline 0 & 1,50 & 258 & 1,66 & 237 & 2,40 & 372 & 447 & 329 \\
\hline 60 & 2,10 & 1.495 & 2,55 & 1.038 & 2,59 & 1.631 & 683 & 1.212 \\
\hline 120 & 2,28 & 1.916 & 3,02 & 1.525 & 2,56 & 1.910 & 792 & 1.535 \\
\hline 180 & 2,31 & 2.011 & 2,92 & 1.618 & 2,65 & 2.077 & 782 & 1.604 \\
\hline 240 & 2,25 & 2.025 & 2,93 & 1.977 & 2,55 & 2.281 & 763 & 1.762 \\
\hline \multicolumn{9}{|l|}{ Parcelamentos: } \\
\hline 1. & & 1.748 & & 1.693 & & 1.913 & 935 & 1.572 \\
\hline 2. & & 1.705 & & 1.358 & & 2.056 & 521 & 1.410 \\
\hline 3. & & 2.088 & & 1.539 & & 2.070 & 841 & 1.634 \\
\hline 4. & & 1.908 & & 1.569 & & 1.790 & 721 & 1.497 \\
\hline \multicolumn{9}{|l|}{ Fonte anterior: } \\
\hline Sulfato de amônio & & 1.922 & & 2.015 & & 2.144 & 755 & 1.709 \\
\hline Nitrocálcio & & 2.126 & & 1.672 & & 2.197 & 915 & 1.728 \\
\hline Uréia & & 1.915 & & 1.392 & & 1.681 & 593 & 1.395 \\
\hline Salitre-do-chile & & 1.485 & & 1.079 & & 1.807 & 756 & 1.281 \\
\hline C.V. (\%) & & 38 & & 39 & & 30 & 63 & 16 \\
\hline DMS (1\%) & & 819 & & 688 & & 687 & 545 & 278 \\
\hline$(5 \%)$ & & 635 & & 534 & & 533 & 423 & 216 \\
\hline
\end{tabular}

As produções obtidas nos tratamentos cujas aplicações de nitrogênio foram realizadas de uma só vez, em outubro ou em dezembro, não diferiram entre si e foram também iguais àquelas do tratamento 3. A produção obtida no tratamento 4 , durante o quadriênio, foi maior que aquelas obtidas nos tratamentos 1 ou 2 , ao nivel de $1 \%$, que a obtida no tratamento 3 ao nivel de $5 \%$ de probabilidade. 
Os dados de produção das parcelas em que se aplicara anteriormente o salitre-do-chile, foram inferiores, a $1 \%$ de probabilidade, aos obtidos nas parcelas em que haviam sido aplicados o sulfato de amônio, uréia ou Nitrocálcio; o sulfato de amônio apresentou maior produçāo que a uréia ao nivel de 5\% de probabilidade.

Pela observação das produções anuais, verifica-se que houve uma oscilação de produção bianual e que as precipitações durante os anos foram bem distribuldas, havendo em 1974/75 um periodo com deficiência hídrica, mais acentuada em agosto, que poderia ter reduzido a produção do ano seguinte. Outro periodo de deficiência em fevereiro de 1977 teria reduzido a produção do ano por falha na granação.

QUADRO 3. Precipitação (P) e deficiência hídrica (DH), durante os períodos, em Campinas

\begin{tabular}{lrrrrrrrrrr}
\hline Mês & $1975 / 76$ & $1976 / 77$ & $1977 / 78$ & $1978 / 79$ & $1979 / 80$ \\
& P & DH & P & DH & P & DH & P & DH & P & DH \\
& 24 & 61 & 182 & 0 & 143 & 0 & 46 & 0 & 89 & 0 \\
Setembro & 24 & 0 & 126 & 0 & 72 & 13 & 115 & 0 & 140 & 0 \\
Outubro & 215 & 0 & 100 & 0 & 150 & 0 & 176 & 0 & 160 & 0 \\
Novembro & 252 & 0 & 100 & 0 & 173 & 0 & 213 & 0 \\
Dezembro & 181 & 0 & 177 & 0 & 286 & 0 & 173 & 0 \\
Janeiro & 261 & 0 & 381 & 0 & 52 & 24 & 154 & 0 & 295 & 0 \\
Fevereiro & 276 & 0 & 56 & 16 & 53 & 39 & 157 & 0 & 132 & 0 \\
Março & 166 & 0 & 123 & 0 & 99 & 13 & 123 & 0 & 51 & 16 \\
Abril & 85 & 0 & 132 & 0 & 9 & 58 & 107 & 0 & 204 & 0 \\
Maio & 151 & 0 & 15 & 6 & 68 & 0 & 104 & 0 & 20 & 8 \\
Junho & 86 & 0 & 32 & 7 & 63 & 0 & 0 & 8 & 88 & 0 \\
Julho & 139 & 0 & 12 & 28 & 63 & 0 & 47 & 0 & 4 & 10 \\
Agosto & 105 & 0 & 29 & 32 & 1 & 38 & 81 & 0 & 35 & 14 \\
\hline
\end{tabular}

Obs.: Dados cedidos pela Seção de Climatologia Agrícola.

\subsection{Experimento da Estação Experimental de Ribeirão Preto}

Os resultados obtidos na Estação Experimental de Ribeirão Preto Quadro 6 - indicam que não houve diferença significativa para as quantidades de 120,180 e $240 \mathrm{~g}$ de $\mathrm{N}$ aplicadas. A produção obtida com $60 \mathrm{~g}$ de $\mathrm{N}$ foi menor ao nivel de $5 \%$, e a ausência de $\mathrm{N}$ produziu menos ao nivel de $1 \%$. 
O parcelamento do $\mathrm{N}$ revelou maior produção ao nivel de $1 \%$ para o tratamento 4 no quadriênio 1975/1979 e no biênio 1975/1976, não havendo constatação de quaisquer outras diferenças.

QUADRO 4. Produção de café beneficiado e teor de $\mathrm{N}$ nas folhas (verão) obtidos na Estação Experimental de Mococa

\begin{tabular}{|c|c|c|c|c|c|c|c|c|c|c|c|}
\hline \multirow{2}{*}{$\frac{N \text { aplicado }}{\text { g/cova }}$} & \multicolumn{2}{|c|}{$1975 / 76$} & \multicolumn{2}{|c|}{$1976 / 77$} & \multicolumn{2}{|c|}{$1977 / 78$} & \multicolumn{2}{|c|}{$1978 / 79$} & \multicolumn{2}{|c|}{$1979 / 80$} & \multirow{2}{*}{$\begin{array}{r}1976 / 80 \\
\mathrm{~kg} / \mathrm{ha}\end{array}$} \\
\hline & $\% \mathrm{~N}$ & $\mathrm{~kg} / \mathrm{ha}$ & $\% \mathrm{~N}$ & $\mathrm{~kg} / \mathrm{ha}$ & $\% \mathrm{~N}$ & $\mathrm{~kg} / \mathrm{ha}$ & $\% \mathrm{~N}$ & $\mathrm{~kg} / \mathrm{ha}$ & $\% \mathrm{~N}$ & $\mathrm{~kg} / \mathrm{ha}$ & \\
\hline 0 & 2,70 & 266 & 2,30 & 103 & 1,75 & 368 & 2,64 & 239 & 2,10 & 458 & 292 \\
\hline 60 & 3,05 & 1.458 & 2,70 & 742 & 2,50 & 1.628 & 3,01 & 624 & 2,82 & 1.145 & 1.035 \\
\hline 120 & 3,14 & 1.572 & 3,06 & 976 & 2,61 & 2.370 & 2,92 & 567 & 2,79 & 2.136 & 1.512 \\
\hline 180 & 3,29 & 1.616 & 3,19 & 1.066 & 2,74 & 2.464 & 3,11 & 664 & 3,05 & 2.066 & 1.565 \\
\hline 240 & 3,14 & 1.694 & 3,06 & 1.098 & 2,71 & 2.662 & 3,24 & 532 & 3,28 & 2.726 & 1.754 \\
\hline \multicolumn{12}{|l|}{ Parcelamentos: } \\
\hline 1. & & 1.674 & & 964 & & 2.158 & & 396 & & 1.744 & 1.316 \\
\hline 2. & & 1.478 & & 724 & & 2.260 & & 477 & & 1.798 & 1.314 \\
\hline 3. & & 1.551 & & 1.043 & & 2.102 & & 911 & & 1.934 & 1.498 \\
\hline 4. & & 1.636 & & 1.152 & & 2.614 & & 602 & & 2.596 & 1.741 \\
\hline \multicolumn{12}{|l|}{ Fonte anterior } \\
\hline Sulfato de amônio & & 1.565 & & 1.406 & & 2.612 & & 865 & & 2.381 & 1.816 \\
\hline Nitrocálcio & & 1.801 & & 984 & & 2.479 & & 523 & & 2.346 & 1.583 \\
\hline Uréia & & 1.567 & & 966 & & 2.543 & & 441 & & 2.096 & 1.511 \\
\hline Salitre-do-chile & & 1.406 & & 526 & & 1.501 & & 557 & & 1.250 & 958 \\
\hline C.V. (\%) & & 12 & & 35 & & 24 & & 50 & & 43 & 22 \\
\hline DMS (1\%) & & 226 & & 390 & & 624 & & 340 & & 989 & 360 \\
\hline$(5 \%)$ & & 175 & & 302 & & 492 & & 264 & & 768 & 280 \\
\hline
\end{tabular}

O efeito das fontes anteriormente utilizadas também não se evidenciou a $1 \%$ de probabilidade. Apenas a $5 \%$ de probabilidade é que o salitre-do-chile mostrou-se prejudicial à produção em relação ao sulfato de amônio, não havendo diferenças entre as demais comparações.

As produções anuais não se mostraram em ciclos bianuais, tendo provavelmente as deficiências hídricas ocorridas no inverno e inicio de primavera de 1975 e 1977 provocado decréscimo de produção dos anos seguintes - Quadro 7. 
QUADRO 5. Precipitação (P) e deficiência hídrica (DH), durante os períodos, em Mococa

\begin{tabular}{|c|c|c|c|c|c|c|c|c|c|c|c|c|}
\hline \multirow[t]{2}{*}{ Mês } & \multicolumn{2}{|c|}{$1974 / 75$} & \multicolumn{2}{|c|}{$1975 / 76$} & \multicolumn{2}{|c|}{$1976 / 77$} & \multicolumn{2}{|c|}{$1977 / 78$} & \multicolumn{2}{|c|}{$1978 / 79$} & \multicolumn{2}{|c|}{$1979 / 80$} \\
\hline & $\mathrm{P}$ & $\mathrm{DH}$ & $\mathbf{P}$ & DH & $\mathbf{P}$ & DH & $\mathbf{P}$ & DH & $\mathbf{P}$ & DH & $\mathbf{P}$ & $\mathrm{DH}$ \\
\hline Setembro & 18 & 61 & 44 & 51 & 221 & 0 & 116 & 0 & 62 & 11 & 179 & 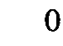 \\
\hline Outubro & 102 & 0 & 93 & 4 & 85 & 0 & 121 & 0 & 87 & 17 & 93 & 1 \\
\hline Novembro & 109 & 0 & 364 & 0 & 210 & 0 & 157 & 0 & 325 & 0 & 180 & 0 \\
\hline Dezembro & 310 & 0 & 171 & 0 & 319 & 0 & 232 & 0 & 250 & 0 & 300 & 0 \\
\hline Janeiro & 162 & 0 & 220 & 0 & 363 & 0 & 264 & 0 & 196 & 0 & 401 & 0 \\
\hline Fevereiro & 308 & 0 & 362 & 0 & 27 & 30 & 69 & 8 & 246 & 0 & 211 & 0 \\
\hline Març & 34 & 23 & 224 & 0 & 157 & 0 & 126 & 0 & 69 & 3 & 67 & 3 \\
\hline Abril & 83 & 0 & 107 & 0 & 181 & 0 & 44 & 14 & 48 & 8 & 156 & 0 \\
\hline Maio & 20 & 20 & 91 & 0 & 6 & 8 & 102 & 2 & 114 & 0 & 12 & 12 \\
\hline Junho & 5 & 32 & 59 & 0 & 48 & 2 & 33 & 3 & 0 & 7 & 91 & 0 \\
\hline Julho & 22 & 17 & 93 & 0 & 5 & 34 & 46 & 3 & 21 & 10 & 0 & 16 \\
\hline Agosto & 0 & 79 & 109 & 0 & 43 & 27 & 1 & 27 & 23 & 32 & 0 & 42 \\
\hline
\end{tabular}

Ob.: Dados cedidos pela Seçāo de Climatologia Agrícola.

QUADRO 6. Produçăo de café beneficiado e teor de $\mathrm{N}$ nas folhas (verão) obtidos na Estaçăo Experimental de Ribeirăo Preto

\begin{tabular}{|c|c|c|c|c|c|c|c|c|c|}
\hline \multirow{2}{*}{$\begin{array}{l}\text { Quantidade de } \mathbf{N} \\
\text { g/cova }\end{array}$} & \multicolumn{2}{|c|}{$1975 / 76$} & \multicolumn{2}{|c|}{$1976 / 77$} & \multicolumn{2}{|c|}{$1977 / 78$} & \multicolumn{2}{|c|}{$1978 / 79$} & \multirow{2}{*}{$\frac{1975 / 79}{\mathrm{~kg} / \mathrm{ha}}$} \\
\hline & $\% N$ & kg/ha & $\% \mathrm{~N}$ & kg/ha & $\% N$ & $\mathrm{~kg} / \mathrm{ha}$ & $\% \mathrm{~N}$ & $\mathrm{~kg} / \mathrm{ha}$ & \\
\hline 0 & 3,08 & 458 & 3,09 & 990 & 2,60 & 625 & 3,36 & 328 & 600 \\
\hline 60 & 3,25 & 712 & 3,75 & 1.374 & 3,01 & 1.315 & 3,27 & 615 & 1.004 \\
\hline 120 & 3,26 & 785 & 3,86 & 1.734 & 3,22 & 1.510 & 3,51 & 738 & 1.192 \\
\hline 280 & 3,32 & 725 & 3,83 & 1.814 & 3,18 & 1.537 & 3,41 & 872 & 1.237 \\
\hline 240 & 3,26 & 657 & 3,89 & 1.424 & 3,12 & 1.571 & 3,27 & 790 & 1.111 \\
\hline \multicolumn{10}{|l|}{ Parcelamentos: } \\
\hline 1. & & 587 & & 1.307 & & 1.519 & & 687 & 1.025 \\
\hline 2. & & 797 & & 1.530 & & 1.329 & & 755 & 1.103 \\
\hline 3. & & 586 & & 1.624 & & 1.315 & & 699 & 1.056 \\
\hline 4. & & 910 & & 1.885 & & 1.771 & & 874 & 1.360 \\
\hline \multicolumn{10}{|l|}{ Fonte anterior: } \\
\hline Sulfato de amônio & & 972 & & 1.702 & & 1.404 & & 854 & 1.233 \\
\hline Nitrocalcio & & 796 & & 1.376 & & 1.471 & & 674 & 1.079 \\
\hline Ureia & & 543 & & 1.707 & & 1.751 & & 747 & 1.187 \\
\hline Salitre-do-chile & & 575 & & 1.561 & & 1.307 & & 740 & 1.046 \\
\hline C.V. (\%) & & 28 & & 25 & & 41 & & 55 & 18 \\
\hline DMS (1\%) & & 232 & & 453 & & 700 & & 471 & 230 \\
\hline$(5 \%)$ & & 181 & & 351 & & 543 & & 366 & 178 \\
\hline
\end{tabular}


QUADRO 7. Precipitação (P) e deficiência hídrica (DH) durante os períodos, em Ribeirão Preto

\begin{tabular}{|c|c|c|c|c|c|c|c|c|c|c|}
\hline \multirow[t]{2}{*}{ Mês } & \multicolumn{2}{|c|}{$1974 / 75$} & \multicolumn{2}{|c|}{$1975 / 76$} & \multicolumn{2}{|c|}{$1976 / 77$} & \multicolumn{2}{|c|}{$1977 / 78$} & \multicolumn{2}{|c|}{$1978 / 79$} \\
\hline & $\mathbf{P}$ & $\mathrm{DH}$ & $\mathbf{P}$ & DH & $\mathbf{P}$ & $\mathrm{DH}$ & $\mathrm{P}$ & $\mathrm{DH}$ & $\mathbf{P}$ & $\mathrm{DH}$ \\
\hline Setembro & 12 & 81 & 49 & 52 & 134 & 4 & 84 & 4 & 48 & 26 \\
\hline Outubro & 133 & 0 & 110 & 0 & 128 & 0 & 76 & 41 & 158 & 0 \\
\hline Novembro & 132 & 0 & 376 & 0 & 187 & 0 & 172 & 0 & 235 & 0 \\
\hline Dezembro & 162 & 0 & 192 & 0 & 290 & 0 & 274 & 0 & 248 & 0 \\
\hline Janeiro & 182 & 0 & 201 & 0 & 342 & 0 & 239 & 0 & 193 & 0 \\
\hline Fevereiro & 190 & 0 & 315 & 0 & 93 & 2 & 133 & 0 & 228 & 0 \\
\hline Março & 15 & 35 & 212 & 0 & 131 & 0 & 151 & 0 & 69 & 4 \\
\hline Abril & 129 & 0 & 42 & 7 & 293 & 0 & 7 & 21 & 97 & 0 \\
\hline Maio & 3 & 19 & 111 & 0 & 6 & 9 & 79 & 0 & 122 & 0 \\
\hline Junho & 0 & 31 & 17 & 5 & 24 & 14 & 44 & 3 & 0 & 8 \\
\hline Julho & 27 & 12 & 104 & 0 & 3 & 43 & 64 & 0 & 25 & 9 \\
\hline Agosto & 0 & 78 & 103 & 0 & 19 & 53 & 0 & 32 & 19 & 36 \\
\hline
\end{tabular}

Obs.: Dados cedidos pela Seção de Climatologia Agrícola.

\section{CONCLUSŌES}

1. A dose de $120 \mathrm{~g}$ de $\mathrm{N}$ por ano e por planta foi suficiente para uma produção de aproximadamente $1.500 \mathrm{~kg}$ de café beneficiado por hectare ou $1,0 \mathrm{~kg}$ de café beneficiado por planta, no caso do espaçamento utilizado no experimento, nos três locais obsenvados. As doses crescentes maiores proporcionaram pequenos incrementos.

2. Os estudos de parcelamento das doses de $\mathrm{N}$ deverão ser complementados para estabelecer a vantagem ou não de sua utilização, uma vez que no todo não mostrou efeito consistente.

3. O efeito residual dos fertilizantes anteriormente aplicados ainda afetou as produções, após dez anos das últimas adubações. 


\section{SUMMARY}

\section{NITROGEN FERTILIZER FOR COFFEE - RATES AND SPLITTED APPLICATIONS OF LIME AMMONIUM NITRATE}

Three experiments were carried out beginning in $1973 / 74$ in a Red Latosol transition to Clay Red Yellow Latosol at the Centro Experimental of Campinas, in a Red-Yellow Podzolic Soil at Estação Experimental of Mococa, and on a Ortho Red Latosol at Estação Experimental of Ribeirão Preto, State of São Paulo, Brazil, in order to study nitrogen application on the coffee tree. Lime ammonium nitrate was applied at rates of $60,120,180$, and $240 \mathrm{~g}$ of $\mathrm{N}$ per plant in splitted applications as follows: in just one time by October and by December; in two times, by January and February; and in four times by October, December, January, and February. High yield increases were obtained with $\mathrm{N}$ applications rates up to $120 \mathrm{~g}$ of $\mathrm{N}$ per plant. With higher rates further yield increments were about 5 or $10 \%$. The residual effects of ammonium sulfate, lime ammonium nitrate, Chilean nitrate and urea were still present ten years after the last application. The data on coffee yield obtained with splitted applications of $\mathrm{N}$ were not consistent.

Index terms: coffee tree; fertilization; nitrogen; rates; splitted applications; residual effects.

\section{AGRADECIMENTOS}

Agradecemos à Srta. Emelinda de Fátima Rodrigues dos Santos, escriturária estagiária da Seção de Café, os serviços de datilografia.

\section{REFERÊNCIAS BIBLIOGRÁFICAS}

MORAES, F.R.P. de; GALLO, J.R.; IGUE, T. \& FIGUEIREDO, J.I. Efeito de três fertilizantes acidificantes sobre a concentração de alumínio e de manganês em folhas e raízes de cafeeiro. Bragantia, Campinas, 38:7-17, 1979.

; LAZZARINI, W; TOLEDO, S.V.; CERVELLINI, G.S. \& FUJIWARA, M. Fontes e doses de nitrogênio na adubaçāo química do cafeeiro. I - Latossolo roxo, transição para Latossolo Vermelho-Amarelo, orto. Bragantia, Campinas, 35:63-77, 1976.

; CERVELLINI, G.S.; TOLEDO, S.V.; MORAES, M.V.; REIS, A.J. \& ROCHA, T.R. Fontes e doses de nitrogênio na adubação química do cafeeiro. Latossolo Roxo e Podzólico Vermelho-Amarelo, orto. Bragantia, Campinas, 44(1):1-15, 1985. 